\title{
Research in Statics Education - Do Active, Collaborative, and Project-Based Learning Methods Enhance Student Engagement, Understanding, and Passing Rate?
}

\author{
Sudhir Mehta, Zhifeng Kou \\ North Dakota State Univeristy
}

\begin{abstract}
Studies involving the effect of interactive engagement teaching methods on student performance in the field of physics education research show a significant difference in the understanding of main concepts between a group of non-traditionally taught students and a group of traditionally taught students. However, no such research is published in the area of engineering and statics.
\end{abstract}

This paper describes and analyzes the impact of several active, collaborative, and project-based learning methods on student engagement, understanding, and passing rate in statics classes. This research was done over a period of three semesters. These research-based educational materials and methods were implemented in statics classes, with an enrollment of about 100 students per section. The students were given pre and post Math-Statics Baseline (MSB) tests to determine the gain in understanding statics materials. The results of the test in these classes are compared with the results from traditionally taught classes (lecture classes with typical testing).

Also, classroom surveys of student engagement (which have been adapted from the National Survey of Student Engagement) and student ratings of the class using the IDEA instrument were conducted in statics classes. The survey results from an experimental class are compared with the results from a traditional class and also with the university and national averages.

The results of this study indicate that when the educational research-based methods and materials were used, student performance on the MSB test has gone up. The average response on the survey of student engagement of the experimental group was significantly higher than the average responses of the traditional class and the university and national averages. The student rating of the experimental classes was significantly higher than the average level of student ratings in the IDEA national database. Also, classroom attendance and passing rates were higher in the experimental classes than the rates in the traditional classes.

\section{Introduction}

Educational research in the late $20^{\text {th }}$ century has seen the evolution of unconventional teaching methods like co-operative learning, peer instruction, critical thinking exercises, and classroom assessment. ${ }^{1-8}$ Patricia Cross, ${ }^{9}$ a leading educator, indicated in her American Association of Higher Education's (AAHE's) 1998 National Conference keynote address that, "We have more 
information about learning available to us than ever before in the history of the world." Herbert Simon, a Nobel Laureate, in his 1997 Frontiers in Education Conference plenary session, said, "Knowledge about human learning processes has developed to the point where we can do better."

A report from the National Research Council $^{7}$ describes basic principles having profound implications for teaching and learning. Also, the Education Commission of the States ${ }^{10}$ describes twelve attributes of good practice in delivering undergraduate education. Using these and other resources, twelve Next Generation (NG) Principles have been suggested by Mehta and Danielson. ${ }^{11}$ The Next Generation Principles are organized into three groups: overarching, foundational, and advanced (see Figure 1). The overarching group has basic guiding principles common to all teaching and learning activities. The foundational principles are specifically relevant to engineering education - principles that without which the advanced principles generally do not succeed. The advanced principles are based on the enhanced learning resulting from the use of methods like active collaborative learning, peer instruction, and service learning.

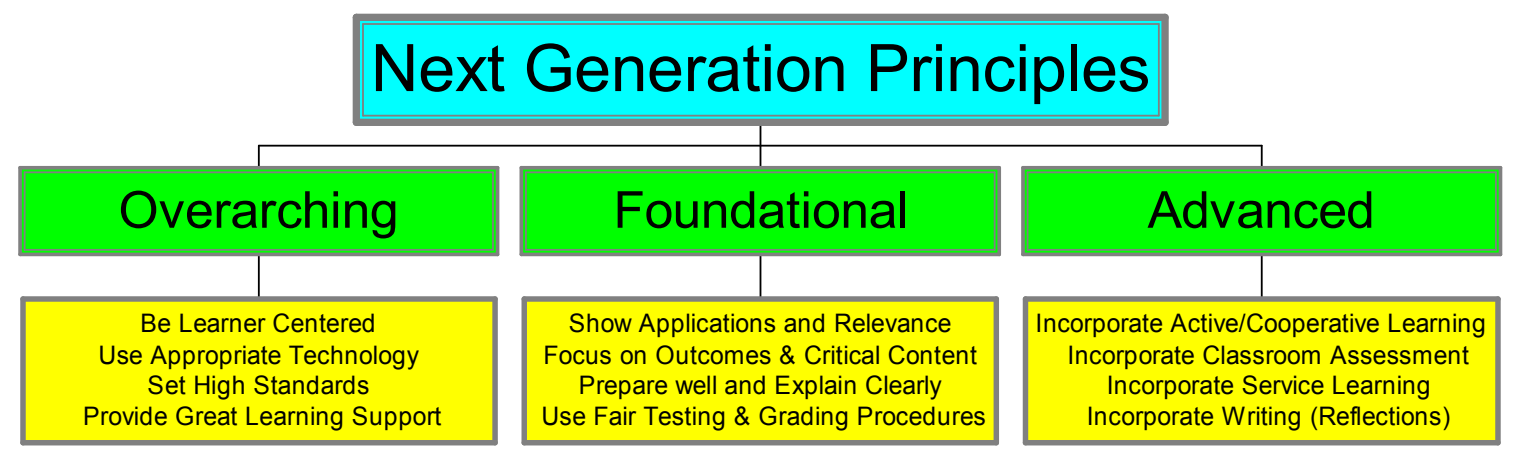

Figure1 Organization of the Next Generation Principles.

The fundamental belief underlying all these Next Generation principles is that as an instructor, one deeply cares about student learning and believes that one can make a difference in their lives. With this belief in place, instructors can explore different ways to help students reach their highest potential. As new findings come from the frontiers of brain research, cognitive science, genetics engineering, etc., even teaching strategies can be reshaped to enhance student learning.

The two sections on the education materials and the implementation procedure are described in Appendix A. They are included mainly for statics instructors interested in knowing and implementing the education materials that have been developed and published by prentice-Hall.

\section{Assessment Tools}

To evaluate the effectiveness of the experimental teaching pedagogy, four assessment tools were used to compare the results from two groups over a period of three semesters. The experimental group consisted of three sections taught using experimental teaching pedagogy; the control group consisted of three sections taught using the traditional method. The four assessment tools are the Math-Statics Baseline (MSB) Test, the classroom survey of student engagement, the classroom survey of student ratings of the class using IDEA instrument, and the passing rate of this course. 
The MSB Test consists of ten math questions and ten static questions. ${ }^{12}$ The math portion probes algebra, geometry, trigonometry, vector algebra, and calculus topics typically used in statics. The statics portion probes knowledge of equilibrium of a particle and a rigid body, structures, friction, internal forces, centroids, and moments of inertia. The questions were intended to be straightforward and require only simple calculations. Students were allowed to bring a calculator, paper, and pencil to the test and there was no time limit. Typically, it took between 20 to 60 minutes to complete the test. The tests given in the first week of a semester were called pretests. In the last week of the same semester, the exact same tests, called posttests, were given to assess what they had learned and to help them prepare for the final examination.

The Survey of Student Engagement (SSE) is designed to measure the student engagement at the class level and consists of 14 questions adapted from the National Survey of Student Engagement (NSSE) (see Appendix B). ${ }^{13}$ The NSSE is an ongoing research campaign in the United States used to assess the extent to which colleges focus on higher levels of learning and personal development. The survey examines the environment of college students, but is also intended to foster a particular way of thinking and talking about collegiate quality. ${ }^{14}$ In the development of the SSE, key questions were selected based on their measurability of student engagement at the classroom level with relation to the level of collaborative learning, cognitive development, and personal skills development. Only fourteen questions were chosen in order to create a modest survey that was appropriate for quick distribution in a variety of different courses.

The Individual Development and Educational Assessment (IDEA) Center, ${ }^{15}$ located at the Kansas State University in Manhattan, KS, was established in 1975 with the emphasis on improving teaching and learning at the higher educational institutions. The IDEA student ratings instrument was made available to nation-wide colleges and universities. The Center tailors each report to fit the instructor's teaching objectives. Teaching effectiveness is determined by student progress on goals chosen by the instructor. Based on their research on their very large national database, the Center also provides national perspective and diagnostic assistance. Fairness is improved by taking into account the influence of factors outside the instructor's control and adjusting the scores. These factors are student work habits, student desire to take the course regardless of who taught it, instructor reported class size, student effort not attributable to the instructor, and course difficulty not attributable to the instructor.

Finally, the students' passing rates in the experimental class and in the traditionally taught class were compared. The passing cut-off grade is kept at $\mathrm{C}$ since students with $\mathrm{D} / \mathrm{F}$ grades in statics are required to retake the class before taking higher level classes in mechanical engineering department.

\section{Results}

MSB Tests: Table 1 shows the students' average pre and post test scores in math and statics and the standard deviations in them. For the purpose of confidentiality, the exact numbers of students in different sections are not reported, but the third week enrollment in each section was approximately 100 students. 
The pre-test scores indicate that at $99 \%$ confidence level (two tailed $\mathrm{p}<.01$ ), there are no significant differences in math and statics scores among the different sections. The average math score is about $84 \%$, which indicates that students on average are coming into a statics class with a reasonable basic math background. The average statics score is about $30 \%$, which indicates that students hardly know much statics. It is important to know that each question on the $\mathrm{MSB}^{12}$ test has four choices. Hence, simple guessing can give a score of $25 \%$. For each math and statics question, students also reported their confidence level (low, medium, or high). Overall, the math confidence level was high, while the statics confidence level was low.

Table 1 Comparison of two groups in MSB Test

\begin{tabular}{|l|c|c|c|c|c|c|c|c|}
\hline \multirow{2}{*}{ Statics Sections } & \multicolumn{4}{|c|}{ Pre Test Score \% } & \multicolumn{4}{c|}{ Post Test Score \% } \\
\cline { 2 - 9 } & \multicolumn{2}{|c|}{ Math } & \multicolumn{2}{c|}{ Statics } & \multicolumn{2}{c|}{ Math } & \multicolumn{2}{c|}{ Statics } \\
\cline { 2 - 9 } & Average & S.Dev & Average & S.Dev & Average & S.Dev & Average & S.Dev \\
\hline Experimental -1 & 86 & 11 & 29 & 13 & 94 & 10 & 72 & 23 \\
\hline Experimental -2 & 85 & 11 & 30 & 16 & 94 & 8 & 72 & 21 \\
\hline Experimental -3 & 83 & 11 & 32 & 15 & 91 & 10 & 71 & 23 \\
\hline Traditional -1 & 85 & 11 & 33 & 15 & 90 & 12 & 56 & 22 \\
\hline Traditional -1 & 80 & 12 & 29 & 13 & 86 & 13 & 44 & 23 \\
\hline Traditional -1 & 84 & 11 & 29 & 14 & 87 & 17 & 55 & 21 \\
\hline
\end{tabular}

The math post-test scores indicate that the average gains in scores are in the range of 3 to $9 \%$. The average math score in experimental sections is $93 \%$ (with a gain of $8 \%$ compared to the pretest average score). The average math score in traditional sections is $88 \%$ (with a gain of $5 \%$ ). However, the gains between the two groups are not significantly different $(\mathrm{p}<.01)$. The average gain in statics scores in experimental sections is $42 \%$ (from $30 \%$ to $72 \%$ ), while the average gain in traditional sections is $21 \%$ (from $30 \%$ to $51 \%$ ). The gains in statics scores in experimental sections are significantly higher $(\mathrm{p}<.01)$ than the gains in any of the traditional sections. The statics confidence level indicated by students in all sections is between medium to high.

Survey of Student Engagement: The surveys of student engagement were conducted in all sections. The results in all experimental sections are similar to each other; so are the results in the traditional sections. Hence, for simplicity, results from a typical experimental and a traditional section are reported and compared with the university and national averages. The results indicated that the scores in all three parts and the total are significantly higher $(\mathrm{p}<.01)$ in the experimental sections compared to the scores in traditional sections and university and national averages.

Table 2 Student Engagement Survey Results

\begin{tabular}{|l|c|c|c|c|}
\hline & Part A & Part B & Part C & Total \\
\hline Range of possible scores & $4-16$ & $5-20$ & $5-20$ & $14-56$ \\
\hline Experimental & 11.1 & 15.5 & 15.9 & 42.7 \\
\hline Traditional & 7.7 & 13.9 & 13.7 & 34.8 \\
\hline University Average & 8.77 & 11.90 & 13.33 & 34.01 \\
\hline National Average & 9.7 & 13.56 & 14.93 & 38.19 \\
\hline
\end{tabular}

Proceedings of the 2005 American Society for Engineering Education Annual Conference \& Exposition Copyright. 2005, American Society for Engineering Education 
Students' Attendance and Passing Rate. A small portion of the total grade (about $10 \%$ each) in experimental sections is kept for the daily quizzes and daily homework. This encourages students to come to all the classes. As they attend almost all the classes and do daily work, they have good continuity and better understanding of the subject. An average student takes much longer to comprehend missed material, and if the material is not studied quickly, it may affect the understanding of the next topic. Romer ${ }^{16}$ has found that attendance in typical large classes is only about 55\% and it affects grades. The Personal Response System (PRS) (Appendix A) used in experimental sections allows instructors to monitor the attendance easily, and it provides quick assessment of daily learning to students and instructors. In the experimental statics sections, the attendance ranged from 85 to 100 percent throughout the semester.

Table 3 Comparison of Students' Passing Rates

\begin{tabular}{|l|c|c|c|c|c|c|c|c|}
\hline & \multicolumn{3}{|c|}{$\%$ of Students Getting A/B/C } & \multicolumn{4}{c|}{$\%$ of Students Getting D/F or } \\
\hline & A & B & C & Total & D & F & Dropping & Total \\
\hline Experimental -1 & 25 & 47 & 20 & 92 & 0 & 3 & 6 & 8 \\
\hline Experimental -1 & 39 & 45 & 14 & 98 & 1 & 1 & 0 & 2 \\
\hline Experimental -1 & 26 & 42 & 20 & 88 & 2 & 1 & 9 & 12 \\
\hline Traditional Teaching - 1 & 11 & 17 & 17 & 45 & 14 & 28 & 14 & 55 \\
\hline Traditional Teaching - 2 & 16 & 24 & 21 & 62 & 10 & 14 & 15 & 39 \\
\hline Traditional Teaching - 3 & 19 & 29 & 24 & 72 & 12 & 7 & 10 & 28 \\
\hline
\end{tabular}

The passing rate of students taught by two different methods also confirmed the previous results. The average percentage of students' getting $\mathrm{A} / \mathrm{B} / \mathrm{C}$ in three experimental teaching sections was $92.6 \%$, compared with $59.2 \%$ in traditionally taught sections. The individual results are reported in Table 3. The percentage of students is calculated based on third-week enrollment numbers. Hence, percentage of students dropped is based on those students who dropped the class after third-week of classes.

Student Ratings of Progress on Relevant Objectives in IDEA Survey. By considering the nature of the statics course, three essential objectives were identified: 1) gaining factual knowledge; 2) learning fundamental principles and theories; and 3) learning to apply course material. In addition to the three essential objectives, five important objectives were identified: 1) developing professional skills; 2) acquiring team skills; 3 ) developing creative capacities; 4) developing oral and written communication skills; and 5) learning more by asking questions and seeking answers. The result (Table 4) demonstrated that the student rating on each single objective in experimental sections was significantly higher than the national averages reported by IDEA center. ${ }^{17}$ The IDEA center reports that the adjusted T scores of 45 to 55 correspond to the middle $40 \%$ of the score distribution. ${ }^{17} \mathrm{~T}$ scores higher than 63 correspond to the highest $10 \%$ of the score distribution. In seven out of eight categories, the $\mathrm{T}$ scores for an experimental section were higher than the 90 percentile level. In four out of eight categories, the $\mathrm{T}$ scores for an experimental section were equal to or higher than the 70 or 98 percentile level. The adjusted average ratings for experimental sections, on a scale of 1 to 5 , were significantly higher than the IDEA average values in all eight categories.

Proceedings of the 2005 American Society for Engineering Education Annual Conference \& Exposition Copyright. 2005, American Society for Engineering Education 
Table 4 Student progress ratings on the major objectives

\begin{tabular}{|l|c|c|c|}
\hline Essential Objectives & $\begin{array}{l}\text { Adjusted T } \\
\text { Score }\end{array}$ & $\begin{array}{c}\text { Average (5-Point } \\
\text { Scale) }\end{array}$ & $\begin{array}{c}\text { IDEA } \\
\text { Average }\end{array}$ \\
\hline Gaining factual knowledge & 65 & 4.7 & 4.0 \\
\hline Learning principles and theories & 70 & 4.9 & 3.9 \\
\hline Learning to apply course material & 72 & 5.0 & 4.0 \\
\hline Important objectives & \multicolumn{3}{|l|}{} \\
\hline Developing professional skills & 70 & 5.0 & 4.0 \\
\hline Acquiring team skills & 64 & 4.8 & 3.9 \\
\hline Developing creative capacities & 68 & 5.0 & 3.9 \\
\hline $\begin{array}{l}\text { Developing Oral and written } \\
\text { communication skills }\end{array}$ & 59 & 4.4 & 3.8 \\
\hline $\begin{array}{l}\text { Learning more by asking my own } \\
\text { questions and seeking answers }\end{array}$ & 72 & 5.0 & 3.8 \\
\hline
\end{tabular}

\section{Discussion and Conclusions}

Richard Hake ${ }^{3}$ published a major study in 1998 in the field of physics education research. He analyzed pre/post-data of mechanics diagnostic/concept tests for 62 introductory physics courses enrolling a total of 6,542 students. He revealed that "traditional courses failed to convey conceptual understanding to the average student"; however, interactive-engagement (IE) courses can be much more effective than traditional courses in enhancing conceptual understanding. In his definition, ${ }^{18}$ the IE courses are the courses using the methods "designated at least in part to promote conceptual understanding through interactive engagement of students in heads-on (always) and hands-on (usually) activities that yield immediate feedback through discussion with peers and/or instructors, all as judged by their literature descriptions." In his study, 14 courses were taught in a traditional way, and 48 courses were taught using the IE methods. The results showed that students in traditional courses achieved a "gain" of 0.23 , while students in IE courses achieved a gain of 0.48 .

However, there is no data available on the effectiveness of IE methods in the engineering statics course for a large number of students. The educational research-based methods implemented in the statics course at NDSU were derived from the novel NG principles, and exactly fall into Hake's definition of IE method. The NDSU study was conducted over a period of three semesters and included over 600 students. The NDSU results also were along the same line with his results in physics education. From the gains in students' final passing rate, the MSB tests, the student engagement survey, to the IDEA report, all of the results demonstrated the superiority of NG principles and educational research-based teaching over the traditionally teaching method.

The IDEA Center ${ }^{17}$ analyzes the individual class results of its standard survey based on its large national database and recommends teaching practices that need to be improved and teaching practices that need to be retained. For our experimental section, the IDEA Center recommended ten teaching practices that need to be retained and none were recommended for improvement. The teaching practices that were found to be effective and were recommended to be retained are 1) found ways to help students answer their own questions; 2) inspired students to set and 
achieve goals which really challenged them; 3) introduced stimulating ideas about the subject; 4) explained the reasons for criticisms of students' academic performance; 5) stimulated students to intellectual effort beyond that required by most courses; 6) demonstrated the importance and significance of the subject matter; 7) made it clear how each topic fit into the course; 8) asked students to help each other understand ideas or concepts; 9) gave projects, tests, or assignments that required original or creative thinking; and 10) formed "teams" or "discussion groups" to facilitate learning.

In spite of glaring success in experimental sections, it is important to note several points, also noted by Hake ${ }^{19}$ in "Lessons from Physics-Education-Reform Effort." First, the use of interactive engagement and/or high-tech methods, by themselves, does not guarantee superior student learning. The foundational principles mentioned earlier and a supportive/motivational learning environment are necessary for the advanced principles to enhance student learning. Second, high quality standardized tests for measuring the cognitive and affective impact of a course need to be developed. The MSB test has only 10 statics questions and needs to be expanded and used on a larger scale at other universities. Third, although methods based on the NG principles appear to be much more effective than traditional methods, there is a need for more research to develop better strategies for continuously enhancing student learning and study their long-term impact. Fourth, cooperation between several disciplines like cognitive psychology, neurology, sciences, engineering, and education is required. Fifth, various institutional policies related to promotion and tenure, including the culture of research universities, must be changed to enhance student learning. Finally, this paper provides an example of what our students can achieve when they are provided with a research-based proper learning environment. William Ouchi ${ }^{20}$ has provided several similar examples in his book, "Making Schools Work: a Revolutionary Plan to Get Your Children the Education They Need." He has shown that by following basic principles that enhance student achievement, overall student performance can be significantly improved, irrespective of the students' race or background. He encourages all of us in the business of educating students by stating: ${ }^{20}$

Above all, I want to encourage you to keep at it, even when you are discouraged, tired, and frustrated. Don't give up. Remember this quotation from Gabriela Mistral, the Chilean poet and Nobel Laureate: Many things can wait; the child can not. Now is the time his bones are being formed; his hand is being developed. To him, we can not say tomorrow; his name is today.

\section{Acknowledgement}

We thank Dr. Richard Shaw from the Center for Writers at North Dakota State Univeristy for his help in the preparation of this manuscript.

\section{References}

1. Angelo, T.A. \& Cross, P. (1993). Classroom Assessment Techniques: A Handbook for College Teachers. Jossey Bass Publisher, San Francisco, CA. 
2. Boyer (1998). "Reinventing Undergraduate Education: A Blueprint For America's Research Universities," $A$ report from the Carnegie Foundation, http://notes.cc.sunysb.edu/Pres/boyer.nsf/

3. Hake, R. (1998). "Interactive-engagement versus traditional methods: A six thousand-student survey of mechanics test data for introductory physics courses," Am. J Phys., 66 (1), 64-74.

4. Johnson, D., Johnson, R., \& Smith, K. (1998). “Cooperative Learning returns to college: What evidence is there that it works?" Change, July/August, 27 - 35.

5. Mazur, Eric (1997). Peer Instruction. Prentice Hall, NJ.

6. McKeachie, W. J. (1999). Teaching Tips: Strategies, Research, and Theory for College and University Teachers, $10^{\text {th }}$ ed., Houghton Mifflin, Boston, MA.

7. NRC (2000). "How people learn: Brain, Mind, Experience, and School (expanded edition)." National Research Council's Commission on Behavioral and Social Sciences and Education: Developments $n$ the Science of Learning and Learning Research and Educational Practice. National Academy Press, Washington, D.C. Full text can be found at http://books.nap.edu/catalog/9853.html

8. NSF (1996). "Shaping the Future: New Expectations for Undergraduate Education in Science Mathematics, Engineering, and Technology, Report \# NSF 96-139.” The National Science Foundation, Arlington, VA.

9. Cross, Patricia (1998). "What Do We Know About Student Learning and How Do We Know It?" in Proceedings of the 1998 AAHE National Conference on Higher Education, Atlanta, GA.

10. ECS (1996). "What Research Says about Improving undergraduate education,” AAHE Bulletin, April, pp. 5-8.

11. Mehta, Sudhir and Scott Danielson. (2000). "Next Generation Principles for Enhancing Student Learning," Proceedings, ASEE National Conference, St. Louis, MO, June 2000.

12. Mehta, S. and Danielson, S. (2002). "Math-Static Baseline (MSB) Test: Phase I." Proceedings of the 2005 American Society of Engineering Education Annual Conference \& Exposition. Session 2268.

13. Ahlfeldt S, Mehta S, and Sellnow T (2005). "Measurement and analysis of student engagement in university classes where varying levels of PBL methods of instruction are in use." Higher Education Research \& Development. Vol 24, No. 1, February 2005, pp.5-20.

14. Kuh, G.D. (2001, May/June). "Assessing what really matters to student learning: Inside the National Survey of Student Engagement." Change, 10-66.

15. IDEA Center. (2003). URL: http://www.idea.ksu.edu. Retrieved on Dec 17, 2003.

16. Romer, D. (1993). "Do Students Go to Class? Should They?” Journal of Economic Perspective, 7, pp.167-174.

17. IDEA Center. (2003). “The IDEA Report for Mehta, S.” Spring 2002-2003.

18. Hake, R. (2000). "Towards paradigm peace in physics education research," Presented at the annual meeting of the American Educational Research Association, New Orleans, April 24-28, 2000.

19. Hake, R (2002). "Lessons from the physics education reform effort." Conservation Ecology 5(2): 28. [online] URL http://www.consecol.org/vol5/iss2/art28/

20. Ouchi, W.G. (2003). Making School Work: A Revolutionary Plan to Get Your Children the Education They Need. Simon and Schuster, New York, NY.

Proceedings of the 2005 American Society for Engineering Education Annual Conference \& Exposition Copyright. 2005, American Society for Engineering Education 
21. Danielson, Scott and Sudhir Mehta. (2001). "Teaching Resources for the New Millennium: Statics as an Example," Journal of SMET Education: Innovations and Research, Vol.2, Issues 1\&2, pp.37-45, 2001.

22. Hibbeler R.C. (2003). Engineering Mechanics-Statics. $10^{\text {th }}$ edition. Prentice Hall, NJ.

23. Mafi, M. (1989). "Involving Students in a Time-Saving Solution to the Homework Problem," Engineering Education, April, p.444.

24. Yokomoto, C.F. and Ware, R. (1991). "The Seven Practices - Persuading Students to do Their Homework," Proceedings of the ASEE Annual Conference, New Orleans, LA, pp.1767-1769.

25. Mehta, S. I. (1997). "Productive, Quick, and Enjoyable Assessment," Proceedings of ASEE National Conference, Milwaukee, WI.

26. Mehta, S.I. (1993). “An Attention Quiz; A Low-Tech, High Yielding Teaching Tip,” Proceedings of the 1993 ASEE Annual Conference, Urbana, IL, pp. 1897-1901.

\section{Biography}

SUDHIR MEHTA, Ph.D., is a professor of Mechanical Engineering at North Dakota State University (NDSU). He received numerous awards from the NDSU and professional societies, including the ASEE, and several grants from the NSF, 3M, and HP to enhance engineering education. He is a Fellow Member of the ASEE, and co-author of the courseware, "Statics: The Next Generation," which is electronically published by Prentice-Hall in August 2001.

ZHIFENG KOU is a Ph.D. candidate in Mechanical Engineering and a Master degree student in Computer Science at North Dakota State University. His research interests are biomechanics of head/neck injury, bioinstrumentation, neuro-engineering, medical informatics, telemedicine and e-health, and engineering education. He is a student member of the ASEE and authored various journal and conference papers in his concentration areas.

\section{Appendix A Educational Materials and Implementation Procedure}

\section{Materials Based on the Next Generation Principles}

Mehta and Danielson have specifically developed instructional materials for Statics. ${ }^{21}$ These materials have been published by Prentice-Hall and are linked (via the use of pictures and illustrations) to the textbook Engineering Mechanics Statics by R.C. Hibbeler. ${ }^{22}$ Similar materials have also been developed and published by Prentice-Hall for Dynamics classes. The materials consist of Lecture Notes containing the topics covered in class, and a variety of quiz questions, and Student Notes which students are meant to read before coming to class. The lecture notes are arranged in PowerPoint slides in a particular fashion, so that they are covered in sequence as the class progresses.

The first slide of each lecture presentation has well defined student-learning objectives. This helps students identify clearly what they are expected to know and are able to do after the lecture. The slide also helps the instructor focus the class discussion on the main topics at hand 
and the assessment of whether the students have achieved the objectives. This slide also lists things to be done during the class period. The lists of objectives and in-class activities give students a clear idea about the overall picture and structure of the lecture (hence satisfying both global and sequential learners). The second slide of the presentation is a Reading Quiz (RQ). ${ }^{5}$ It usually consists of two multiple-choice questions based on the reading assignment for that day's class. It is expected that students come to the class prepared by reading the Student Notes and the assigned reading from the textbook. The RQ questions are simple and straightforward. The students use answer sheets or personal response software to record their homework grades and answers to the quiz questions. Coming prepared to the class is an important part of students taking ownership of their learning. This also facilitates useful classroom discussion and spending classroom time on more difficult topics. After the reading quiz, there are some pictures depicting real-life applications of that day's topic, which stems from the NG Principle of showing applications and relevance of the material. These pictures raise student curiosity, create an incentive and motivation to learn the material, and also inform the student of the relevance of the topic in the industry. After discussing the applications, the relevant theory and concepts are discussed. This might be considered as a mini-lecture. These materials are based on "critical content" (key points for desired student outcomes and difficult material, as per the NG Principle of focusing on outcomes and critical content). The mini-lecture is followed by an example showing how the theory or concept just discussed can be applied to solve a problem. This example immediately reinforces the material for the students. After the solved example, there is a Concept Quiz (CQ). The CQs are usually two multiple-choice questions. They attempt to probe into a deeper understanding of a concept, rather than simply plugging numbers into equations. They are solved using peer instruction and cooperative learning. The CQ is followed by a groupsolving problem to be solved by the groups of two or three students. It is important that students have an opportunity to solve a problem right away, as soon as a topic has been discussed. This helps to quickly clarify many of the doubts and questions that students typically have. This assessment situation also provides the instructor a natural opportunity to act as a coach to the students in their learning. The last event of the class period is another set of two multiple-choice questions based on the day's material. These questions may require simple calculation or may be concept-based.

The Student Notes are an altered version of the Lecture Notes and are prepared and given to the students ahead of the class period. This is done for several reasons. Students should come to class prepared and take ownership of their own learning. Classroom time should be spent in active engagement or discussion of what they already know, real-life applications and relevance, critical content, concept questions, and group problems. Students' time spent blindly copying notes from the board or screen is minimized if they spend some time before the class reading this material. Whatever the delivery method, it is advantageous for the students to have the notes before the day of class so they can use them to prepare.

\section{Implementation Procedure}

At North Dakota State University (NDSU), over 200 students from various engineering majors take statics each semester. Typically, two sections of about 100 students each are offered every semester. Following is a running description of how an experimental class with the Next Generation materials was conducted: 
Each class-lecture is of 75-min. duration (twice-a-week schedule). In the first lecture, the class is divided into several groups of four students each, and each group is given a number. Groupmembers are asked to sit near each other in all lectures. The groups are selected at random, that is, without anyone's preference. Members of each group are given leader numbers L1, L2, L3, and L4. Every member is the leader of his/her group once every four lectures. So if L1 is the leader of his group for one lecture, then L2 is the leader of that group for the next Statics lecture, and L3 for the succeeding lecture, and so on. This gives every student a chance to lead his student team. The leader is expected to come prepared to the class with his/her group-problem solved (discussed later). Also the leader has to solve a leader-quiz, which is based on that day's topic, and submit the solution in class. So the class begins with the submission of leader quizzes by the respective group leaders for that lecture. These leader quizzes are graded by the instructor / TA later.

The class proceeds with students grading two to three assigned homework problems from the text. Here, students grade their neighbor's homework, ${ }^{23}$ and are thus introduced to peer assessment. The instructor uses an overhead projector or PowerPoint slide to display the solution and discuss it. To prepare the students for the grading, procedures and practice grading are done at the start of the semester. Students receive a numerical score out of ten. The grading procedure is explained to the students. Each mistake (diagram, units, etc.) takes away one mark, so that the grading is uniform. To minimize the temptation of cheating, students are asked to have homework graded by different graders, with the graders required to sign-off on the graded homework paper. Also, students are required to save the homework in their class portfolio notebook for periodic review by the instructor. Students need to correct their mistakes, if any, on their homework, quizzes, and tests as soon as possible after they have been graded. They are also informed that the main purpose of homework is to learn the subject matter, and there is a strong correlation between effort on the homework and test scores. ${ }^{24}$ Grades are entered by students into the instructor's computer through a Personal Response System (PRS). This whole exercise takes about 15 minutes.

As the next event in the class period, a reading quiz (RQ) is given. The answers are recorded as explained above for the homework grades. After the answers are recorded, a verbal response from the class is obtained. This verbal response gives instant feedback to the instructor about the student responses to the quiz. The instructor then confirms and explains the correct response. Then various applications of the day's topic are discussed. These applications serve as an introduction to a mini-lecture addressing critical content. Included in this mini-lecture is the coverage of the day's main topics and one to two basic example problems. This process usually takes another 30 minutes. Next, students are given a set of concept quizzes (CQ). They are asked to discuss the CQ and enter their individual choice of answers on the PRS; the responses are recorded. Next, students participate in group problem-solving using a standard problem given at the end of a chapter. Finally, an attention quiz (AQ) is given. ${ }^{25-26}$ This quiz consists of one or two multiple-choice questions based on the main ideas emphasized in that day's class. The last two activities take about 25 minutes (for a total time of 70 minutes in a 75 minutes lecture).

The students are also requested to volunteer three hours of their time during the semester to help other statics students during the group problem-solving sessions. The student volunteers are 
required to study the group problem before the class period. To enhance instructor-student communication, a list-serv is used to send e-mail to all students, on an as-needed basis. Students also keep a portfolio, write three to four reference journals, and work on two to three openended, real-life design projects.

\section{Appendix B Survey Form of Student Engagement}

\section{A Survey of Student Engagement}

Course Number:

Instructor:

\section{Please cross $(\mathrm{X})$ your answers.}

A. During your class, about how often have you done each of the following? Scale: 4: very often; 3: often; 2: occasionally; 1: never

\begin{tabular}{|c|c|c|c|c|}
\hline 1. Asked questions during class or contributed to class discussions & 4 & 3 & 2 & 1 \\
\hline 2. Worked with other students on projects during class time & 4 & 3 & 2 & 1 \\
\hline 3. Worked with classmates outside of class to complete class assignments & 4 & 3 & 2 & 1 \\
\hline 4. Tutored or taught the class materials to other students in the class & 4 & 3 & 2 & 1 \\
\hline
\end{tabular}

B. To what extent has this course emphasized the mental activities listed below? Scale: 4: very much; 3: quite a bit; 2: some; 1: very little

\begin{tabular}{|c|c|c|c|c|}
\hline $\begin{array}{l}\text { 5. Memorizing facts, ideas or methods from your course and readings so you can repeat } \\
\text { them in almost the same form }\end{array}$ & 4 & 3 & 2 & 1 \\
\hline $\begin{array}{l}\text { 6. Analyzing the basic elements of an idea, experience or theory such as examining a } \\
\text { specific case or situation in depth and considering its components }\end{array}$ & 4 & 3 & 2 & 1 \\
\hline $\begin{array}{l}\text { 7. Synthesizing and organizing ideas, information, or experiences into new, more } \\
\text { complicated interpretations and relationships }\end{array}$ & 4 & 3 & 2 & 1 \\
\hline $\begin{array}{l}\text { 8. Evaluating the value of information, arguments, or methods such as examining how others } \\
\text { gathered and interpreted data and assessing the accuracy of their conclusions }\end{array}$ & 4 & 3 & 2 & 1 \\
\hline 9. Applying theories and/or concepts to practical problems or in new situations & 4 & 3 & 2 & 1 \\
\hline
\end{tabular}

C. To what extent has this course contributed to your knowledge, skills, and personal development in the following ways?

\section{Scale: 4: very much; 3: quite a bit; 2: some; 1: very little}

\begin{tabular}{|l|c|c|c|c|}
\hline 10. Acquiring job or career related knowledge and skills & 4 & 3 & 2 & 1 \\
\hline 11. Writing clearly, accurately, and effectively & 4 & 3 & 2 & 1 \\
\hline 12. Thinking critically and/or analytically & 4 & 3 & 2 & 1 \\
\hline $\begin{array}{l}\text { 13. Learning effectively on your own, so you can identify, research, and complete a } \\
\text { given task }\end{array}$ & 4 & 3 & 2 & 1 \\
\hline 14. Working effectively with other individuals & 4 & 3 & 2 & 1 \\
\hline
\end{tabular}

